\title{
Congenital malformations and maternal occupation in Finland: multivariate analysis
}

\author{
K. HEMMINKI, P. MUTANEN, I. SALONIEMI, AND K. LUOMA \\ From the Institute of Occupational Health, Helsinki
}

SUMmaRY The Finnish Register of Congenital Malformations was used in a multivariate analysis to explore the associations between maternal occupation in industry and children born with central nervous system (CNS) or musculoskeletal or oral cleft malformations. Possible confounding factors were selected in preliminary screening of risk indicators for malformations. These factors included characteristics of the mother, the child, and the family; maternal illnesses; and maternal medication at the time of pregnancy. Tobacco smoking was a confounding factor for all types of malformations; number of children born to the mother, maternal age, malformations in the family, number of rooms occupied by the family, sex of the child, threatened abortion, and continuous medication of the mother during the first trimester confounded the association for certain types of malformations. After adjusting for confounding factors, maternal occupation in industrial trades significantly correlated with CNS, oral cleft, and musculoskeletal malformations in the offspring. Maternal occupation in industry and construction only was significantly associated with CNS malformations in the offspring but the associations with oral cleft and musculoskeletal malformations were not significant.

Environmental factors are thought to contribute to the aetiology of congenital malformations because the incidence of these malformations shows a large geographical variation and some seasonal variations. $^{1}$ Furthermore, in migrant families the incidence appears to be adjusted towards the level of the new population which the migrants are joining. ${ }^{2-4}$ Other evidence on the role of environmental factors is the socioeconomic variation in the incidence of congenital malformations observed in many countries. $^{1}$

The environmental factors that cause human malformations appear to be largely unknown. ${ }^{5}$ Yet several chemical factors, such as medicines, have been implicated as being teratogenic to man. . $^{-8}$ Certain kinds of work may lead to exposure to harmful chemicals and some apparently at-risk occupations have been described in the literature. An increased incidence of congenital malformations has been reported in the offspring of operating theatre personnel, ${ }^{9-11}$ vinyl chloride polymerisation workers, ${ }^{12}$ copper smelters, ${ }^{13}$ laboratory technicians, ${ }^{14}$ and people exposed to solvents. ${ }^{15}$ In addition, studies on the relationship of parental occupation to malformations in the offspring have suggested increased risks for certain industrial occupations. ${ }^{16-19}$

We have reported previously that industrial occupations are more often found among mothers of cases than among mothers of controls in the Finnish Register of Congenital Malformations. ${ }^{20}$ The parental occupations were recorded prospectively, thus avoiding the effects of a selective memory bias. However, as the controls were matched only for time and place of birth, the observed associations between industrial occupations and malformations could have been confounded by many factors. In the present study we attempt to control for the effects of these factors using multivariate analysis.

\section{Material and methods}

The Finnish Register of Congenital Malformations has been maintained since 1963 at the National Board of Medicine. It is a case-control register including three types of malformations: central nervous system (CNS), oral cleft, and musculoskeletal. The cases are identified from compulsory notifications filled in at the maternity hospitals. The controls are the previous birth in the maternity welfare district. The cases and the referents are interviewed at the maternity welfare centres by the midwives. The standardised interview forms and the copies of the maternity welfare centre records are sent to the National Board of Medicine for inclusion in the register. The organisation of the register has been described previously in more detail. ${ }^{21}$ 
We coded the maternal occupations based on the records of the maternity welfare centres according to the three-digit classification of the Central Statistical Office of Finland. ${ }^{22}$ As the occupations were collected from the records of the maternity welfare centre, filled in during pregnancy, no selective memory bias could affect the results. All the cases and their referents from 1967 to 1977 were collected, covering a total of about 3300 pairs. A case with multiple malformations was entered separately in each of the appropriate groups of malformations. Other information on the case and the referent mothers, such as age, number of children, smoking habits, and illnesses and medication during the actual pregnancy, was coded by the National Board of Medicine. Most of this information was recorded by interviewing the mothers after the birth of the child and it may thus be subject to memory bias. The effect of maternal occupations on the risk of defects in the offspring was evaluated by calculating odds ratios according to the formula for a matched series (ratio of discordant pairs) ${ }^{23}$ The crude odds ratios obtained were referred to as 'original odds ratios'. McNemar's test was used for the evaluation of statistical significance.

In this study the influence of the possible confounding factors on the association between maternal occupation and malformations in the offspring was estimated using the linear logistic regression model..$^{24-27}$ The parameters of the model were tested as described. ${ }^{26}$

In this model a dichotomous exposure variable, $\mathrm{F}$, and a disease indicator variable, $\mathrm{D}$, are considered, and data of affected (case) and healthy (control) individuals are analysed to ascertain exposure. The model is set for these conditional exposure probabilities:

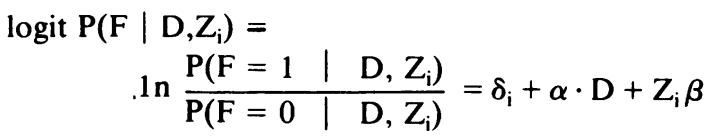

where $D=1$ for cases and $D=0$ for controls; $F=1$ if exposure is present and $F=0$ if it is not present; $Z$ is a vector of confounding factors for the $i$ :th pair (that is, the influence of $Z$ on exposure probabilities is common to both cases and controls). From the above formula the exposure odds ratio (EOR) can be derived:

$$
\begin{aligned}
& \text { 1n }(E O R) \\
& =\operatorname{logit} P\left(F \quad \mid D=1, Z_{i}^{\prime}\right)-\operatorname{logit} P\left(F \mid D=0, Z_{i}^{\prime}\right) \\
& \quad=\alpha+\left(Z_{i}^{\prime}-Z_{i}^{\prime \prime}\right) \cdot \beta \\
& \text { and } \\
& \quad \text { EOR } \\
& \quad=e^{\alpha}, \text { if } Z_{i}^{\prime}=Z_{i}^{\prime \prime}
\end{aligned}
$$

Thus the linear logistic model for matched data assumes the relationship is linear for the log odds ratio. $\alpha$ and $\beta$ are regression parameters. The odds ratio after the elimination of the confounding factors (referred to as 'revised odds ratio') is $\mathrm{e}^{\alpha}$. The parameters $(\alpha$ and $\beta)$ of the model were estimated by the Walker-Dunkan method ${ }^{28}$ and tested by the asymptotically normally distributed statistic $t_{j}=\hat{\beta}_{j} / \operatorname{Se}\left(\hat{\beta}_{j}\right)$

The confounding factors were chosen for the multi variate analysis on the basis that they associated with the three types of malformations in a preliminary screening of the factors and that they were conceivably related to occupation. Table 1 shows all the variables which were taken into the multivariate analysis. Some apparent confounding factors were omitted from the analysis for two reasons, either because they were considered a product of maternal memory bias (for example, reported depressive state during pregnancy), or because they were considered to be caused by the malformation (for example, low birthweight of the child). The factors are considered as binary variables in Table 1 and in the calculation of the original odds ratios for occupation in Tables 2, 3, and 4. In multivariate analysis each confounding factor was described quantitatively in 2 to 10 different categories, increasing or decreasing in magnitude. Only the first trimester of pregnancy was considered and the maternal illnesses and medication were listed in three categories according to the month ( 1 = first, 2 = second, $3=$ third) of pregnancy in which an illness was first contracted or a medication used.

\section{Results}

The risk indicators of malformations considered as possible confounding factors in the association of maternal occupation with malformations in the offspring (see Table 1) were taken into the multivariate analysis. The selection of the possible confounding factors was not stringent in terms of biological or causal considerations, because it turned out that most variables tested did not associate with the occupation. All the 22 different variables were controlleld in groups with each of the three main types of malformations. The groups of variables controlled at one time included maternal factors (three variables), social factors (five variables), factors relating to obstetric history (four), maternal diseases (six), and medication ingested (four). The variables showing a significant $(p<0 \cdot 10)$ association with maternal occupation in industry were considered technically as true confounders, and they were included in the final analysis described in Tables 2 to 4 . 
Table 1 Odds ratios of the risk indicators considered as possible confounders of the association of maternal occupation with malformations in the offspring

\begin{tabular}{|c|c|c|c|}
\hline \multirow[b]{2}{*}{ Risk indicator } & \multicolumn{3}{|c|}{ ODDS RATIOS } \\
\hline & $\begin{array}{l}\text { CNS } \\
\text { malformation }\end{array}$ & Oral cleft & $\begin{array}{l}\text { Musculoskeletal } \\
\text { malformation }\end{array}$ \\
\hline $\begin{array}{l}\text { Maternal age }>35 \\
\text { No. of children born alive } \geq 5 \\
\text { Previous stillbirths: yes } \\
\text { Previous premature births: yes } \\
\text { Previous abortions } \geq 2 \\
\text { Malformations in family: yes } \\
\text { Weight of placenta } \leq 400 \mathrm{~g} \\
\text { Multiparous pregnancy: yes } \\
\text { Sex of child: boy } \\
\text { Number of rooms occupied by family } \leq 1 \cdot 2 \text { person } \\
\text { Tobacco smoking }>5 \text { cigarettes a day }\end{array}$ & $\begin{array}{l}1 \cdot 39^{*} \\
1 \cdot 54^{*} \\
3 \cdot 09^{* * *} \\
2 \cdot 24^{* *} \\
1 \cdot 56 \\
2 \cdot 24^{* * *} \\
3 \cdot 26^{* * *} \\
4 \cdot 38^{* * *} \\
0 \cdot 82^{*} \\
4 \cdot 09^{* * *} \\
1 \cdot 61^{* * *}\end{array}$ & $\begin{array}{l}1 \cdot 27 \\
1 \cdot 23 \\
27 \cdot 00^{* * *} \\
1 \cdot 41 \\
1 \cdot 41 \\
3 \cdot 76^{* * *} \\
3 \cdot 02^{* * *} \\
3 \cdot 10^{* *} \\
1 \cdot 10 \\
1 \cdot 54^{* *} \\
1 \cdot 49\end{array}$ & $\begin{array}{l}1 \cdot 14 \\
1 \cdot 37 \\
1 \cdot 56 \\
1 \cdot 24 \\
1 \cdot 00 \\
3 \cdot 65^{* * *} \\
5 \cdot 48^{* * *} \\
2 \cdot 08^{*} \\
1 \cdot 19^{*} \\
1 \cdot 52^{* *} \\
1 \cdot 35\end{array}$ \\
\hline $\begin{array}{l}\text { Diseases and conditions during pregnancy } \\
\text { Threatening abortion: yes } \\
\text { Influenza 1st trimester } \\
\text { High fever } 1 \text { st trimester } \\
\text { Other disease } 1 \text { st trimester } \\
\text { Chronic illness: yes } \\
\text { No. of diseases } \geq 1\end{array}$ & $\begin{array}{l}1 \cdot 65^{* * *} \\
2 \cdot 56^{* * *} \\
2 \cdot 50^{* * *} \\
2 \cdot 70^{* * *} \\
1 \cdot 64^{* *} \\
1 \cdot 61^{* * *}\end{array}$ & $\begin{array}{l}1 \cdot 52^{* * *} \\
1 \cdot 82^{* * * *} \\
2 \cdot 38^{* * *} \\
2 \cdot 38^{* * *} \\
1 \cdot 56 * * * \\
1 \cdot 72 * * *\end{array}$ & $\begin{array}{l}1 \cdot 77^{* * *} \\
2 \cdot 04^{* * * *} \\
2 \cdot 22 * * * \\
2 \cdot 78^{* * *} \\
1 \cdot 67^{* * *} \\
2 \cdot 78^{* * *}\end{array}$ \\
\hline $\begin{array}{l}\text { Medication and treatment during } 1 \text { st trimester } \\
\text { Analgesics } \\
\text { Antineurotics } \\
\text { Continuous medication } \\
\text { Temporary medication } \\
X \text { rays }\end{array}$ & $\begin{array}{l}2 \cdot 86^{* * *} \\
1 \cdot 92^{*} \\
2 \cdot 22^{* *} \\
1 \cdot 69^{* * *} \\
1 \cdot 83^{* * *}\end{array}$ & $\begin{array}{l}2 \cdot 22^{* * *} \\
2 \cdot 33^{* *} \\
1 \cdot 67^{*} \\
1 \cdot 61^{* * *} \\
1 \cdot 12\end{array}$ & $\begin{array}{l}2 \cdot 63^{* * *} \\
1 \cdot 64 \\
2 \cdot 50^{* * *} \\
1 \cdot 92^{* * *} \\
1 \cdot 65^{* *}\end{array}$ \\
\hline
\end{tabular}

"p $<0.05 ; " * p<0.01 ; \cdots p<<0.0001 ;$ McNemar's test.

Table 2 Influence of the confounding factors on the association of maternal occupation with CNS malformations in the offspring in the linear logistic regression model

\begin{tabular}{|c|c|c|c|c|}
\hline Original odds ratio & $\begin{array}{l}\text { no. of discordant pairs } \\
\text { analysed }\end{array}$ & $\begin{array}{l}\text { After analysis with the following } \\
\text { confounding factors }\end{array}$ & Test statistics ${ }^{1}$ & Revised odds ratio \\
\hline \multicolumn{5}{|c|}{ Mother in industry, construction, transport, communications } \\
\hline $1.49^{* *}$ & 164 & $\begin{array}{l}\text { No. children born } \\
\text { Malformations in family } \\
\text { No. rooms occupied by family } \\
\text { Smoking } \\
\text { Continuous medication }\end{array}$ & $\begin{array}{l}-2 \cdot 50^{*} \\
-1 \cdot 73^{a} \\
-2 \cdot 70^{* *} \\
1 \cdot 18 \\
-2 \cdot 15^{*}\end{array}$ & $1 \cdot 98^{* * *}$ \\
\hline \multicolumn{5}{|c|}{ Mother in industry, construction } \\
\hline $1.62^{* *}$ & 160 & $\begin{array}{l}\text { No. children born } \\
\text { No. rooms occupied by family } \\
\text { Smoking }\end{array}$ & $\begin{array}{r}-3 \cdot 11^{* *} \\
-1 \cdot 74^{a} \\
1 \cdot 91^{a}\end{array}$ & $1 \cdot 81^{* *}$ \\
\hline
\end{tabular}

${ }_{\text {a }}^{1}$ Test statistics indicate the significance of the individual confounding factors.

a $<0.10 ; * p<0.05 ;{ }^{* *} p<0.01 ; * * p<0.001$

Table 3 Influence of the confounding factors on the association of maternal occupation with oral clefts in the offspring in the linear logistic regression model

\begin{tabular}{|c|c|c|c|c|}
\hline Original odds ratio & $\begin{array}{l}\text { No. of discordant pairs } \\
\text { analysed }\end{array}$ & $\begin{array}{l}\text { After analysis with the following } \\
\text { confounding factors }\end{array}$ & Test statistics & Revised odds ratio \\
\hline \multicolumn{5}{|c|}{ Mother in industry, construction, transport, communication } \\
\hline $1 \cdot 26$ & 248 & $\begin{array}{l}\text { Maternal age } \\
\text { Smoking } \\
\text { Threatening abortion }\end{array}$ & $\begin{array}{l}-2 \cdot 22^{*} \\
3 \cdot 25^{* * *} \\
-1 \cdot 87^{a}\end{array}$ & $1 \cdot 38^{*}$ \\
\hline \multicolumn{5}{|c|}{ Mother in industry, construction } \\
\hline $1 \cdot 13$ & 241 & $\begin{array}{l}\text { Maternal age } \\
\text { Smoking }\end{array}$ & $\begin{array}{r}-3 \cdot 42^{* * *} \\
3 \cdot 43^{* * *}\end{array}$ & $1 \cdot 23$ \\
\hline
\end{tabular}

$a_{p}<0 \cdot 10 ;{ }^{*} p<0 \cdot 05 ; * * p<0 \cdot 01 ; * * p<0 \cdot 001$. 
Table 4 Influence of the confounding factors on the association of maternal occupation with musculoskeletal malformations in the offspring in the linear logistic regression model

\begin{tabular}{|c|c|c|c|c|}
\hline Original odds ratio & $\begin{array}{l}\text { No. of discordant pairs } \\
\text { analysed }\end{array}$ & $\begin{array}{l}\text { After analysis with the following } \\
\text { confounding factors }\end{array}$ & Test statistics & Revised odds ratio \\
\hline \multicolumn{5}{|c|}{ Mother in industry, construction, transport, communications } \\
\hline $1 \cdot 35^{*}$ & 253 & $\begin{array}{l}\text { Malformations in family } \\
\text { Sex of child } \\
\text { Smoking }\end{array}$ & $\begin{array}{l}-2 \cdot 13^{*} \\
2 \cdot 48^{*} \\
2 \cdot 71^{* *}\end{array}$ & $1 \cdot 33^{*}$ \\
\hline \multicolumn{5}{|c|}{ Mother in industry, construction } \\
\hline $1 \cdot 30^{*}$ & 225 & $\begin{array}{l}\text { Malformations in family } \\
\text { Sex of child } \\
\text { Smoking }\end{array}$ & $\begin{array}{c}-2 \cdot 08^{*} \\
1 \cdot 74^{\mathrm{a}} \\
2 \cdot 75^{* *}\end{array}$ & $1 \cdot 22$ \\
\hline
\end{tabular}

$\mathrm{a}_{\mathrm{p}<0.10 ;}^{*} \mathrm{p}<0.05 ;{ }^{* *} \mathrm{p}<0.01$

The variables that appeared to confound the association of maternal occupation in industry with CNS malformations in the offspring were the number of children born to the mother, malformations in other family members, number of rooms occupied by the family (probably a social class factor), maternal tobacco smoking habits, and continuous medication of the mother during the first trimester. The controlling of these factors increased the odds ratio from the original 1.49 to $1.98(p<0.001)$ for the offspring of the mothers employed in industry, construction, transport and communications (Table 2). Consideration of the offspring of only industrial and construction workers resulted in a revised odds ratio of 1.81 compared with the original odds ratio of $1 \cdot 62$.

A similar analysis was carried out of the association of maternal occupation in the industrial trades with oral clefts in the offspring (Table 3). After adjustment for maternal age, tobacco smoking, and threatened abortion during the relevant pregnancy, the odds ratio increased from the original 1.26 to $1.38(p<0.05)$. Consideration of only industrial and construction workers increased the odds ratio to $1 \cdot 23$ (non-significant).

Adjustment for the confounding factors (malformations in the family, sex of the child, and smoking habits of the mother) in the analysis of the relationship between industrial occupations and musculoskeletal malformations in the offspring only slightly affected the odds ratio (1.33; Table 4$)$. The odds ratio for the offspring of industrial and construction workers only was smaller, $1 \cdot 22$, after the multivariate analysis.

\section{Discussion}

The original analysis of parental occupation in relation to congenital malformations in the offspring showed increased odds ratios for certain maternal but not paternal occupational groups. ${ }^{29}$ Central nervous system and musculoskeletal malformations were more common in the offspring of industrial and construction workers; oral clefts were more common in the offspring of transport and communication workers. However, as the series was matched only for the time and place of birth, confounding factors related to occupation could affect the observed relationship. In respect of industrial workers, the most likely sources of confounding are the determinants of employment or of social class. These may include age, family size, social habits such as tobacco smoking, dietary and hygienic factors, and illnesses.

In the present multivariate analysis attempts were made to control the confounding factors. Three different types of variables were controlled. The first included characteristics of the mother and the child, and of their family, found to be associated with the three types of malformations in our primary screening. Several variables of this group appeared to confound the association of maternal occupation in industry with malformations in the offspring. The only confounding factor for all types of malformations was tobacco smoking, which has been reported as being associated with malformations in some previous studies, ${ }^{30}{ }^{31}$ whereas no association has been found in other studies. ${ }^{32}$

Another group of variables controlled included maternal illnesses during the first trimester of pregnancy. Of these, maternal influenza and threatened abortion have previously been associated with CNS defects and oral clefts in the offspring. ${ }^{26}{ }^{33}$ Maternal illness could conceivably be a confounder, as certain illnesses appear to be more common among workers compared with managers and office personnel according to a Finnish study ${ }^{34}$ However, in the present analysis, only threatened abortion turned out to be a confounding variable associated with oral clefts.

The third group of variables controlled included the medication ingested and the $x$ ray treatment given. Medicines associated with malformations in our preliminary screening (Table 1 ) are in agreement with other reports. ${ }^{26}{ }^{33}$ The only type of treatment found to be a confounding factor was the reported 
continuous, regular medication of the mother during the first trimester, associating with CNS malformations.

In the present study, based on information accumulated in the Finnish Register of Congenital Malformations, we could control a number of factors confounding the relationship between maternal occupation in industry and malformation in the offspring. Many of the factors controlled were related to social class (for example, smoking habits, number of rooms occupied, family size, etc.) and yet the association of maternal occupation in industrial trades with malformations in the offspring remained. Thus the results do not suggest a mere social class effect. In agreement, analysis of the register according to parental social class revealed no clear gradient. ${ }^{29}$ Yet the possibility remains that the variables available fail to describe social class adequately and that social class would indeed be one of the underlying factors.

One possible source of spurious associations is the design of the register, as the time interval between the delivery and the interview is from two to six months. A deficit of an occupation in the controls may develop if those in that occupation move frequently, or if the number of persons employed decreases rapidly. Such bias should, however, affect all the types of malformations equally; thus the findings of the present study cannot be explained by the bias.

The controlling of the confounding factors either increased or decreased the association of maternal employment in industrial trades with malformation in the offspring. After the multivariate analysis, maternal occupation in industry (industry, construction, transport, and communications) was significantly associated with CNS, oral cleft, and musculoskeletal malformations in the offspring. Central nervous system malformations appeared to be particularly common among the children of industrial and construction workers, while oral cleft and musculoskeletal malformations were common among the children of transport and communications workers, although this group was so small that it could not be analysed separately. Thus some occupational factors may constitute a true risk for the embryo. The identification of the specific agents and factors which constitute the occupational exposures is a challenge to be met in further studies.

We thank Professor O. P. Heinonen, Dr. J. Haapakoski, Ms Anneli Ruusinen, and Ms Pirjo Fahlström.
Reprints from Dr. K. Hemminki; Department of Industrial Hygiene and Toxicology, Institute of Occupational Health, Haartmaninkatu 1, 00290 Helsinki 29, Finland.

\section{References}

${ }^{1}$ Leck I. Correlations of malformation frequency with environmental and genetic attributes in man. In: Wilson JG, Clark FC, ed. Handbook of Teratology, Volume 3. New York: Plenum Press, 1977: 243-324.

${ }^{2}$ Naggan L, MacMahon B. Ethnic differences in the prevalence of anencephaly and spina bifida in Boston, Massachusetts. N Engl J Med 1967; 277: 1119-23.

${ }^{3}$ Leck I. Ethnic differences in the incidence of malformations following migration. Br J Prev Soc Med 1969; 23: 166-73.

${ }^{4}$ Horowitz I, McDonald AD. Anencephaly and spina bifida in the province of Quebec. Can Med Assoc J 1969; 100: 748-55.

${ }^{5}$ Wilson JG. Environment and Birth Defects. New York: Academic Press, 1973: 305.

${ }^{6}$ Shephard TH. Catalogue of Teratogenic Agents, 2nd edn. Baltimore: Johns Hopkins University Press, 1973.

${ }^{7}$ Miller RW. Relationship between human teratogens and carcinogens. J Natl Cancer Inst 1977; 58: 471-4.

${ }^{8}$ Smithells RW. Environmental teratogens of man. Br Med Bull 1976; 32: 27-33.

${ }^{9}$ Knill-Jones RP, Moir DD, Rodrigues LV, Spence AA. Anaesthetic practice and pregnancy: controlled survey of women anaesthetists in the United Kingdom. Lancet 1974 ; i: $1326-8$.

${ }^{10}$ Corbett TH, Cornell RG, Enders JL, Lieding K. Birth defects among children of nurse-anesthetists. Anesthesiology 1974; 41: 341-4.

${ }^{11}$ Tomlin PJ. Health problems of anaesthetists and their families in the West Midlands. $B r \operatorname{Med} J$ 1979; i: 779-84.

${ }^{12}$ Infante PF, McMichael AJ, Wagoner JK, Waxweiler RJ, Falk H. Genetic risks of vinyl chloride. Lancet 1976; i: 734-5.

${ }^{13}$ Nordenström S, Beckman L, Nordenson I. Occupational and environmental risks in and around a smelter in northern Sweden. VI. Congenital malformations. Hereditas 1979; 90: 297-300.

${ }^{14}$ Meirik O, Källen B, Gauffin U, Ericson A. Major malformations in infants born to women who worked in laboratories while pregnant. Lancet 1979; i: 91.

${ }^{15}$ Holmberg PC. Central-nervous-system defects in children born to mothers exposed to organic solvents during pregnancy. Lancet 1979; i 177-9.

${ }^{16}$ Fedrick J. Anencephalus in the Oxford record linkage study area. Dev Med Child Neurol 1976; 18: 643-56.

${ }^{17}$ Bjerkedal T, Lund TE. Yrke og fødsel. Hygienisk Institutt, Universitetet i Oslo 1978; 1-116.

${ }^{18}$ Registrar General. Occupational Mortality 1970-1972. Decennial Supplement for England and Wales. London: HMSO, 1978: 1-224.

${ }^{19}$ Erickson JD, Cochran WM, Anderson CE. Paternal occupation and birth defects. A preliminary report. In: Klingberg MA, Weatherall JAC, ed. Epidemiologic Methods for Detection of Teratogens. Contributions to Epidemiology and Biostatics vol. 1. Basel: S Krager, 1979; 57-70. 
${ }^{20}$ Hemminki K, Saloniemi I, Luoma K, Salonen T, Partanen T, Vainio H, Hemminki E. Transplacental carcinogens and mutagens: childhood cancer, malformations and abortions as risk indicators. $J$ Toxicol Environ Health 1980; 6: 1115-24.

${ }^{21}$ Saxén L, Klemetti A, Härö AS. A matched pair register for studies of selected congenital defects. Am J Epidemiol 1974; 100: 297-306.

${ }^{22}$ Central Statistical Office of Finland. Asunto- ja elinkeino-tutkimuksen ammattiluokitus (Occupational classification for the housing and economing survey). Helsinki: CSOF, 1975.

${ }^{23}$ Miettinen OS. Estimation of relative risk from individually matched series. Biometrics 1970; 26: 75-86.

${ }^{24}$ Prentice $R$. Use of the logistic model in retrospective studies. Biometrics 1976; 32: 599-606.

${ }^{25}$ Cox DR. The analysis of binary data. London: Methuen, 1970.

${ }^{26}$ Granroth G, Haapakoski J, Saxén L. Defects of the central nervous system in Finland. V. Multivariate analysis of risk indicators. Int J Epidemiol 1978; 7: 301-8.

${ }^{27}$ Rossner B, Henneken CH. Analytic methods in matched pair epidemiological studies. Int J Epidemiol 1978; 7: 367-72.
${ }^{28}$ Walker SH, Duncan DB. Estimation of the probability of an event as a function of several independent variables. Biometrika 1967; 54: 167-79.

${ }^{29}$ Hemminki K, Mutanen P, Luoma K, Saloniemi I. Congenital malformations by parental occupation in Finland. Int Arch Occup Environ Health 1980; 46: 93-8.

${ }^{30}$ Himmelberger DU, Brown BW, Cohen EN. Cigarette smoking during pregnancy and the occurrence of spontaneous abortion and congenital abnormality. Am J Epidemiol 1978; 108: 470-9.

${ }^{31}$ Ericson A, Källén B, Westerholm P. Cigarette smoking as an etiological factor in cleft lip and palate. Am J Obstet Gynecol. 1979; 135: 348-51.

${ }^{32}$ Heinonen OP, Slone D, Shapiro S. Birth defects and drugs in pregnancy. In: Kaufman DW, ed. Massachussetts: Publishing Science Group, 1977: 516.

${ }^{33}$ Saxén I. Epidemiology of cleft lip and palate. An attempt to rule out chance correlations. Br J Prev Soc Med 1975; 29: 103-10.

${ }^{34}$ Nyman K, Raitasalo R. Työstä poissaolot ja niihin vaikuttavat tekijät Suomessa. Kansaneläkelaitoksen julkaisuja A 1978; 14: 203. 